\title{
A Simulation-based Comparative Study on Lateral Characteristics of Trucks with Double and Triple Trailers
}

\author{
Yang Chen \\ Research Scientist, \\ Center for Vehicle Systems and Safety, Virginia Tech, VA \\ Email: ychen38@vt.edu \\ Andrew W. Peterson \\ Senior Research Scientist, \\ Center for Vehicle Systems and Safety, Virginia Tech, VA \\ Email: awp20@vt.edu
}

\section{Ce Zhang}

Research Assistant, Center for Vehicle Systems and Safety, Virginia Tech, VA Email: zce@vt.edu

\author{
Mehdi Ahmadian* \\ Dan Pletta Professor and Director, \\ Center for Vehicle Systems and Safety, Virginia Tech, VA \\ Email: ahmadian@vt.edu \\ *Corresponding author
}

\begin{abstract}
This paper investigates the lateral stability and maneuverability in long combination vehicles (LCVs), namely semi-trucks with 28-ft doubles, 28-ft triples, and 33$\mathrm{ft}$ doubles, using TruckSim. In recent years, due to the rapid increase of E-commerce cargo transport demands, trucks with multiple trailers have been used with increasing frequency on U.S. highways. The most common configuration is 28 - $\mathrm{ft}$ doubles, although in some states, 28-ft triples and longer doubles, such as 33-ft trailers, are also allowed. LCVs provide operational advantages in terms of loading and unloading, ease of distribution, and other key logistics that are superior to the conventional 53-ft trailers that are commonly used for bulk cargo over long hauls. The vast proliferation of LCVs on U.S. highways heightens awareness of their dynamics, including lateral stability and maneuverability which are strongly tied to highway safety. This study provides a comparative evaluation of the lateral characteristics for tractors with 28-ft double, 28-ft triple, and 33-ft double trailers. In particular, the likelihood of rollovers, rearward amplification, and off-tracking are analyzed among those LCVs using the multi-domain dynamic models developed in
\end{abstract}


TruckSim. The efforts to validate the truck dynamic model against test results are also included. The simulation results show that trucks with triple trailers exhibit a larger rearward amplification, higher likelihood of rollovers, and larger off-tracking than trucks with double trailers. Additionally, the results indicate that increasing the trailer length from 28 to 33 feet does not increase the likelihood of rollovers or the rearward amplification. In fact, the longer trailers provide a slight amount of additional roll stability due to their longer wheelbase.

Keywords: lateral stability; off-tracking; rearward amplification; rollover; long combination vehicles; 33-ft doubles; TruckSim.

Biographical notes: Yang Chen, Ph.D., is Research Scientist at Center for Vehicle Systems and Safety (CVeSS). Dr. Chen received his Ph.D. in May 2017, and immediately started at his current position at CVeSS. He has performed an extensive amount of dynamic modeling using tools such as TruckSim, SimMechanics, and other simulation tools that is essential to the success of this program.

Andrew W. Peterson, Ph.D., is Senior Research Scientist at CVeSS. Dr. Peterson received his Ph.D. in December 2013 and immediately started at his current position at CVeSS. He has multiple years of practical experience in scientific testing of complex dynamic systems, system instrumentation, data analysis, and design of experiments.

Ce Zhang is a graduate research student at the Department of Mechanical Engineering at Virginia Tech, working in the area of vehicle dynamics. He is expected to complete his Doctoral degree in Mechanical Engineering in 2023.

Mehdi Ahmadian is Dan Pletta Professor of Mechanical Engineering at Virginia Tech, where he also holds the position of Director of Center for Vehicle Systems and Safety (CVeSS), and the Railway Technologies Laboratory (RTL). He has authored more than 130 archival journal publications and more than 250 conference publications, including a number of keynote lectures and 300 technical presentations. He holds ten US and international patents, and has edited four technical volumes. He currently serves as Editor for the International Journal of Vehicle System Dynamics and Editor-in-Chief for Journal of Vibration and Control. He is Fellow of American Society of Mechanical Engineers (ASME), Fellow of the Society of Automotive Engineers (SAE International), and Associate Fellow of the American Institute for Aeronautics and Astronautics (AIAA). 


\section{Introduction}

During the past decade, the dramatic growth of E-commerce and online retail sales have contributed to an increasing need for smaller, lighter goods to be transported and distributed. The U.S. Department of Transportation estimates that from 2012 to 2040, total values of truck transportation weight and shipment will increase by $43 \%$ and $93 \%$, respectively [1]. To accommodate the massive demand for transporting goods, trucks hauling two or more trailers, known as Long Combination Vehicles (LCVs), have become increasingly popular. In 2015, there were 2,746,882 LCVs traveling on the U.S. highways, which is 7.5\% higher than in 2010 [2]. The most prevalent multi-trailer combination is the 28 -ft doubles that are mostly used on rural freeways between less-than-truckload freight terminals. The Surface Transportation Assistance Act (STAA) authorized the 28-ft doubles to operate on all national networks as of 1982 [3].

Compared with the conventional $53-\mathrm{ft}$ single-trailer trucks, the $28-\mathrm{ft}$ doubles render some operational advantages, such as more flexible cargo handling and logistics, and easier maneuvering around tight corners [4]. In addition, longer doubles, such as 33-ft trailers and 28-ft triples, are also used by the less-than-truckload industry and major package express carriers in the U.S due to their increased cubic capacity. A recently-released report from Americans for Modern Transportation [5] claims that a shift from the $28-\mathrm{ft}$ doubles to the $33-\mathrm{ft}$ doubles would provide many benefits, including reducing the number of trucks and trips, less fuel consumption and air pollution, and reducing traffic jams and the driver shortage. The 33-doubles and 28-ft triples, however, are still prohibited from accessing highways in some states, as shown in Figure 1. This limitation is primarily driven by both the infrastructure's potential inability to support the extended vehicle length, and uncertainty regarding any added safety risks.

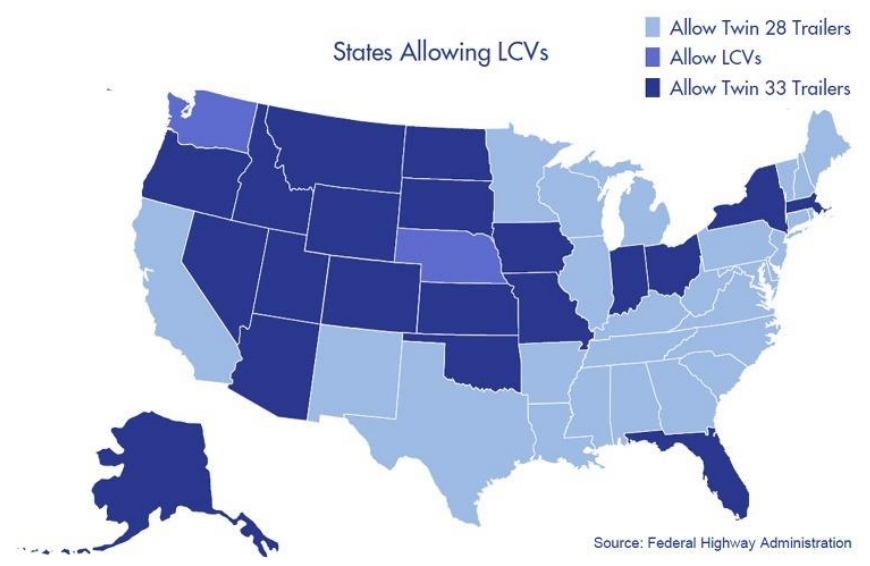

Figure 1. U.S. states allowing the operation of LCVs [6] 
The severity of accidents involving commercial vehicles is often greater than smaller vehicles mainly because of their heavier load and higher center of gravity (CG) [7, 8]. The Federal Motor Carrier Safety Administration statistics indicate that there were 3,864 fatal crashes and 104,000 injury crashes involving large trucks in 2016 [9]. The critical elements that affect LCV safety include rollover characteristics, tracking performance as it relates to the rearward amplification of the trailers, directional control, stability during braking, and steering controllability [10, 11].

This paper focuses on the first two safety elements. This is mainly because rollovers account for $5 \%$ of all fatal crashes involving LCVs [9]. For trucks with multiple trailers, the rearward amplification ("crack-the-whip" effect) associated with the last trailer strongly contributes to lack of tracking and lane keeping, and at times rollovers during quick and evasive maneuvers [12].

Another critical element in LCVs is the large offtracking in intersections, roundabouts, and narrower roads. Obviously, this limits the vehicle's maneuverability, imposes more risk of encroachment into adjacent lanes, and increases the likelihood of collision with other vehicles and fixed objects. Climbing over curbs in intersections and truck aprons in roundabouts could result in the unloading of the wheels on one side, as a result of the tilt of the body, and therefore rollover [13].

There exist very few U.S. studies relative to the lateral dynamic performance of LCVs. Daniels (2006) [14] presented field measurements showing that 28-ft doubles are more stable and offtrack less on curves than the conventional 5-axle single trailer truck. Pape et al. (2011) [4] performed simulations and experiments to study the increased rearward amplification of triple-trailer trucks with increasing speed in lane change maneuvers. Harkey et al. (1996) [13] studied the operational characteristics of LCVs and concluded that the off-tracking at low-to-medium speeds is a major safety concern for Rocky Mountain doubles and turnpike doubles.

In this paper, we extend the previous studies by providing a simulation-based comparative evaluation of the rollover characteristics and off-tracking performance between 28 -ft doubles, 28 $\mathrm{ft}$ triples, and 33-ft doubles. All of the selected LCVs have the semi-trailers coupled with each other by an A-dolly, shown in Figure 2. The A-trains are widely used in the U.S. because of their easier installation as compared with other configurations, such as the B-train. 

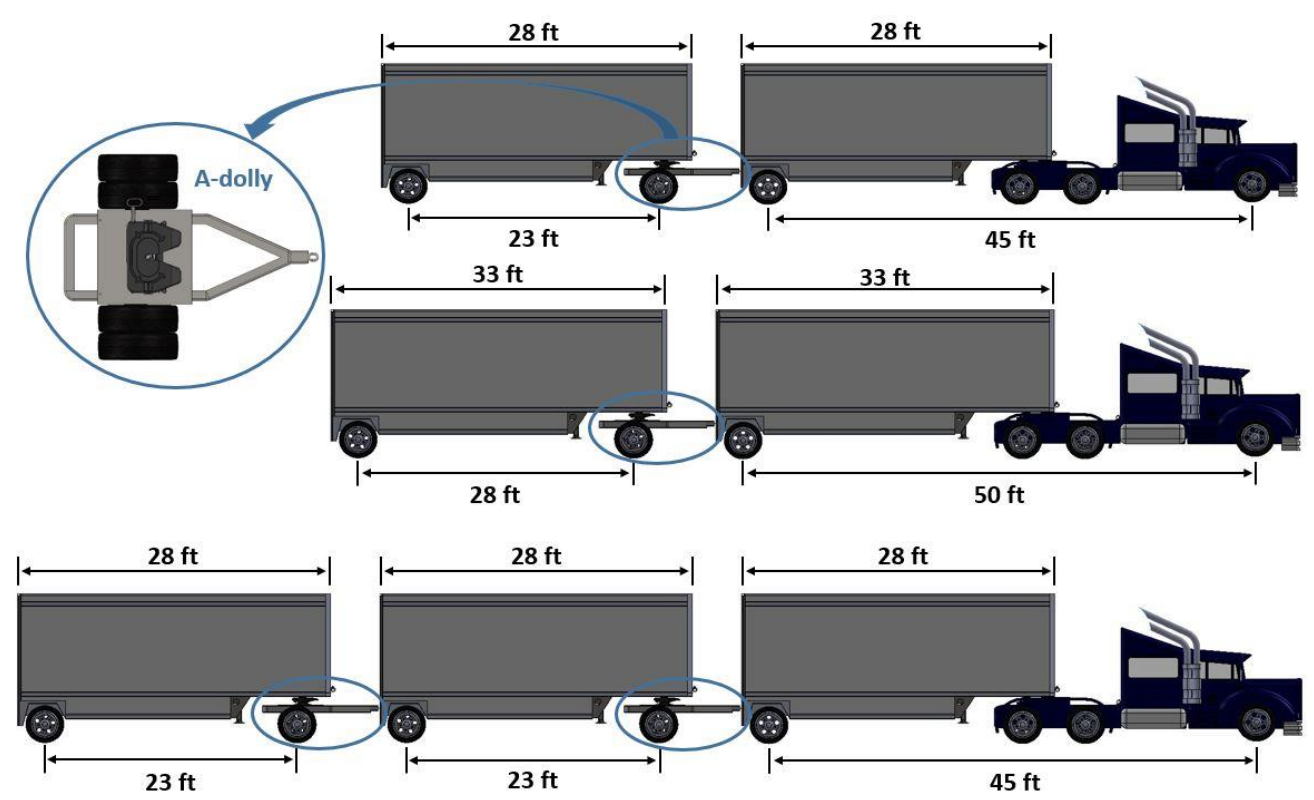

Figure 2. Configurations of $28-\mathrm{ft}$ doubles, $33-\mathrm{ft}$ doubles, and $28-\mathrm{ft}$ triples

In particular, rollover likelihood, rearward amplification, and off-tracking are evaluated under various maneuvers and speeds for drop-frame trailers whose dynamics are not considered in prior studies. The drop-frame trailers shown in Figure 2 are attractive alternatives to the conventional flat-bed trailers due to their larger cargo capacity and lower placement of cargo for reducing cargo CG height. Some U.S. fleets have widely adopted the 28 -ft drop-frame trailers in their operations. TruckSim, a commercial truck dynamics software package, is used to develop the multi-body dynamic model of the tractor-trailer combinations. Detailed descriptions of the tire, suspension, and trailer sub-models are provided. The validation of the model with test results is also included. The validated model is used to perform an extensive simulation to compare and analyze the dynamic performance of the tractor-trailer combinations mentioned earlier. The paper concludes with a discussion of simulation results.

\section{Vehicle Dynamic Model}

This section introduces the multi-body dynamic models of semi-trucks with double and triple trailers developed using TruckSim.

\subsection{8-ft Double-trailer Truck Model}

A 6-axle A-double model is established in TruckSim, as shown in Figure 3, including a $6 \times 4$ tractor and two 28 -ft box van trailers connected by a single-axle dolly hooked up to a pintle hitch on the 
rear of the front trailer. Basic dimensional parameters for the truck simulation, such as vehicle wheelbase, axle track, suspension lateral spacing, etc., are determined by direct measurements on a real truck as shown in Figure 4. For the parameters of the system such as braking, power transmission, etc. that are hard to define, default values in TruckSim are applied. The main parameters used for the tractor and dolly simulation are provided in Table 5 of Appendix A [15]. To ensure the accuracy and effectiveness of the vehicle model in the scope of the study, mathematical calculation and other simulation tools are applied to calibrate the model inputs concerning the yaw and roll dynamics. The model inputs that need to be determined include critical tire properties, pneumatic suspension dynamics, and trailer dimensional inertial (CG) properties.

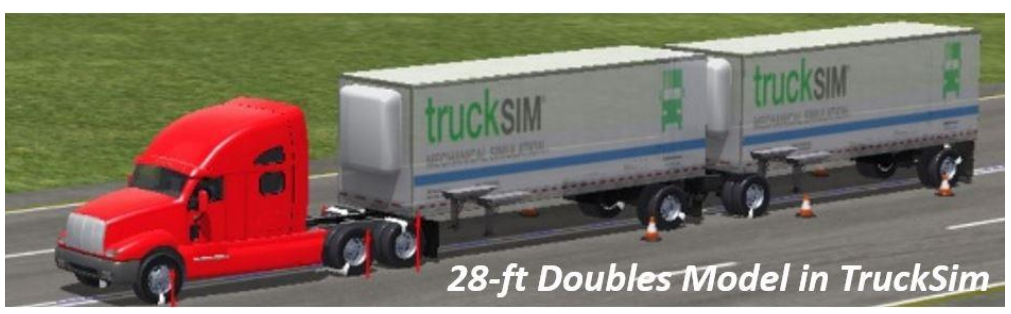

Figure 3. The 28-ft double-trailer truck model in TruckSim

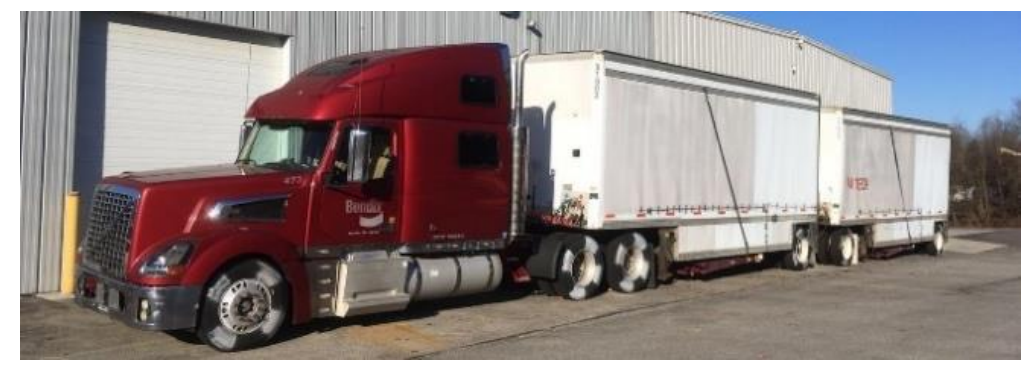

Figure 4. 28-ft double-trailer truck

\subsubsection{Critical Tire Property Setup}

Simulating the dynamics of unsprung mass requires knowledge of the tire properties, especially its vertical stiffness. The load-deflection method is applied to calculate the vertical stiffness of the tire model. Tire manufacturer data are provided in Table 1, which are used to calculate the vertical stiffness by dividing the vertical load by the resulting deflection.

Table 1. Manufacturer data of truck tires

\begin{tabular}{|c|c|c|c|}
\hline Tires & Free Radius $\left(\boldsymbol{R}_{f}\right)$ & Loaded Radius $\left(\boldsymbol{R}_{l}\right)$ & Vertical Load $\left(\boldsymbol{F}_{z}\right)$ \\
\hline Steering Axle & 20.5 in & 18.6 in & $6610 \mathrm{lb}$. \\
\hline Drive Axle & $20.5 \mathrm{in}$ & $19.4 \mathrm{in}$ & $6175 \mathrm{lb}$. \\
\hline Trailer/ Dolly Axle & $19.5 \mathrm{in}$ & $18.6 \mathrm{in}$ & $6175 \mathrm{lb}$. \\
\hline
\end{tabular}


Based on the data in Table 1, the effective radius of the tire is determined by the equation [16]:

$$
R_{e}=\frac{\sin \left(\cos ^{-1} \frac{R_{L}}{R_{f}}\right)}{\cos ^{-1} \frac{R_{L}}{R_{f}}} R_{f}
$$

The effective radius is subsequently applied to calculate the moment caused by the tire rolling resistance force (due to the hysteresis of the tire material as the tire flexes), which has a strong influence on the vehicle longitudinal velocity:

$$
M_{f}=F_{z} R_{e} f_{s}\left(f_{c}+f_{v} v_{x}\right)
$$

where $F_{z}$ is the vertical load, $f_{s}$ is the road surface coefficient ( 1.2 for dry asphalt), $f_{c}$ is the rolling resistance coefficient, here assumed to be a constant value of $0.005, f_{v}$ is the velocity coefficient, set to 0.004 hour/mile, and $v_{x}$ is the longitudinal velocity of the vehicle $[16,17]$. In the tire model, the vital factor that affects the lateral or yaw motion of the vehicle is the lateral tire-road friction force (lateral force). The lateral force for small tire slip angles is linearly approximated as [18]:

$$
F_{y}=-C_{t} \alpha_{i j}
$$

where $C_{t}$ is the tire cornering stiffness, $\alpha_{i j}$ is the slip angle, and $i$ denotes the front or rear axle, where $\mathrm{j}$ means the left or right side. The cornering stiffness is greatly affected by the tire vertical load and construction. In this study, the default data of the tire model in TruckSim is applied to represent the cornering stiffness. The slip angles are calculated geometrically and are given for the steering axle:

$$
\begin{aligned}
& \alpha_{f l}=\tan ^{-1}\left(\frac{v_{y}+\emptyset a}{v_{x}-\emptyset c / 2}\right)-\delta \\
& \alpha_{f r}=\tan ^{-1}\left(\frac{v_{y}+\emptyset a}{v_{x}+\emptyset c / 2}\right)-\delta
\end{aligned}
$$

and for the rear axles on tractor, trailer, and dolly:

$$
\begin{aligned}
& \alpha_{r l}=\tan ^{-1}\left(\frac{v_{y}-\emptyset b}{v_{x}-\emptyset c / 2}\right) \\
& \alpha_{r r}=\tan ^{-1}\left(\frac{v_{y}-\varnothing b}{v_{x}+\varnothing c / 2}\right)
\end{aligned}
$$

where $\delta$ is the steering angle, $v_{x}$ and $v_{y}$ are the longitudinal and lateral velocity of the vehicle, respectively, $\varnothing$ is the yaw rate, $a$ and $b$ are the distance from the CG to the front and rear axles, respectively, and $\mathrm{c}$ is the axle track width [18]. 


\subsubsection{Pneumatic Suspension Dynamic Model Development}

For the LCV application, all axles except the steering axle are commonly equipped with airsprings to render extra roll stability and reduce cargo damage from the road disturbance. In order to reasonably represent the non-linear characteristics of the pneumatic suspension, a thermodynamic model is developed and interpolated into TruckSim. Equations that govern the dynamic behavior of airsprings are derived from the ideal gas law by assuming an isentropic process [19]:

$$
\left(P_{a}+P_{a t m}\right) V_{a}^{\gamma}=\left(P_{a 0}+P_{a t m}\right) V_{a 0}^{\gamma}
$$

where $P_{a}$ and $V_{a}$ are the gauge pressure and inner volume of the airspring, respectively, $P_{a t m}$ is the atmospheric pressure, $P_{a 0}$ and $V_{a 0}$ are the initial gauge pressure and the initial volume of the airspring, respectively, and $\gamma$ is the heat capacity ratio (1.4 for air). Substituting the expression of airspring volume into Equation (8) yields [19]:

$$
\left(P_{a}+P_{a t m}\right)\left[\left(L_{0}+x\right) A_{e}\right]^{\gamma}=\left(P_{a 0}+P_{a t m}\right) V_{a 0}^{\gamma}
$$

where $L_{0}$ is the height of the airspring with a static load, $A_{e}$ is the airspring's effective area, which is a value normally ranging between 0.6 and 0.8 times the geometry area, and $x$ is the suspension deflection. The suspension deflection is positive when the airspring is compressed, and negative when the airspring is extended. Rearranging Equation (9) gives the expression of airspring pressure, which is multiplied by the effective area to produce the equation of airspring force:

$$
F_{a}=A_{e}\left(\frac{\left(P_{a 0}+P_{a t m}\right) L_{0}^{\gamma}}{\left(L_{0}-x\right)^{\gamma}}-P_{a t m}\right)
$$

As Equation (10) indicates, the curve of airspring force to the suspension deflection is dependent on ride height, effective area, and initial pressure. The airsprings on various axles behave dynamically differently from each other due to their different effective areas and ride heights. Specifically, the trailer airspring possesses a larger effective area and lower ride height, resulting in a higher stiffness than that of the tractor and dolly, as shown in Figure 5. Moreover, the airspring on the dolly has a lower stiffness than that of the tractor due to its higher ride height. 


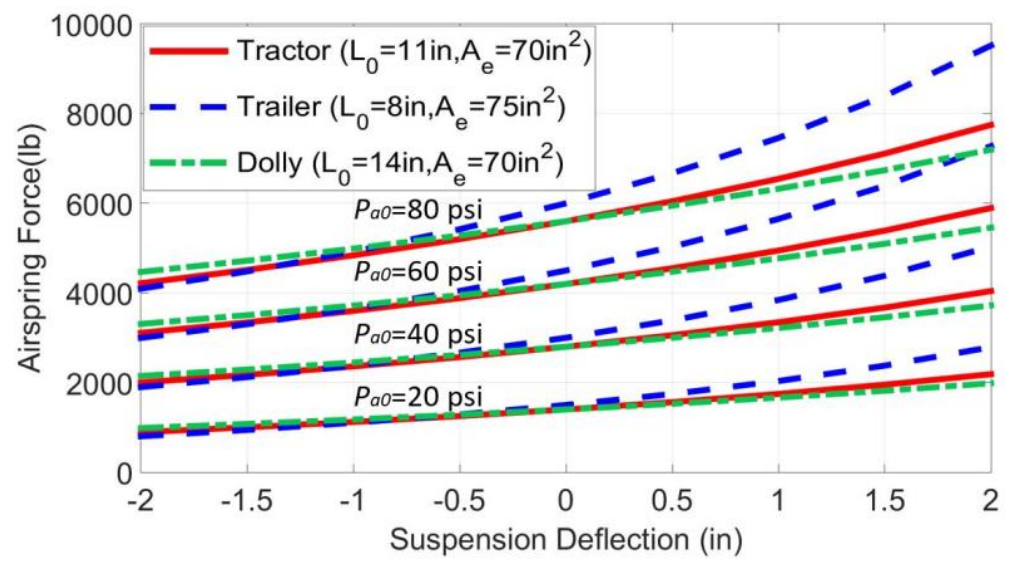

Figure 5. Airspring force with respect to suspension deflection for the airsprings on the tractor, trailer, and dolly

Based on Equation (10), a 3-D surface plot is created to represent the airspring force at various heights and static loads (initial pressures). The 3-D plot is then interpolated into TruckSim to simulate the non-linear characteristics of the pneumatic suspension system.

\subsubsection{Trailer Dimensional Inertial (CG) Property Determination}

To provide the trailer properties necessary for the dynamic simulation, a 3-D model of the 28-ft drop-frame trailer is created in SolidWorks, which is shown in Figure 6. Notably, a red mass (uniform) is placed in the trailer to represent the normal highway load with a weight of $6000 \mathrm{lb}$., and occupying $75 \%$ inner volume of the trailer. Upon assigning corresponding material to each component, the SolidWorks model produces the required parameters, including sprung weight, CG position, and moment of inertia in roll, yaw, and pitch, which are shown in Table 2.

Table 2. Parameters for the 28-ft drop-frame trailer simulation

\begin{tabular}{|c|c|}
\hline Trailer Body Properties & 28-ft doubles \\
\hline Sprung Weight & $14952 \mathrm{lb}$. \\
\hline CG Height to the Ground & $6.22 \mathrm{ft}$ \\
\hline CG Longitudinal Distance to the Kingpin & $11.94 \mathrm{ft}$ \\
\hline Distance from the Kingpin to Axle & $23 \mathrm{ft}$ \\
\hline Roll Moment of Inertia & $251898 \mathrm{lb} \cdot \mathrm{ft}^{2}$ \\
\hline Yaw Moment of Inertia & $1069921 \mathrm{lb} \cdot \mathrm{ft}^{2}$ \\
\hline Pitch Moment of Inertia & $1013789 \mathrm{lb} \cdot \mathrm{ft}^{2}$ \\
\hline Load Weight & $6000 \mathrm{lb}$. \\
\hline Load Density & $3.81 \mathrm{lb} . / \mathrm{ft}^{3}$ \\
\hline
\end{tabular}




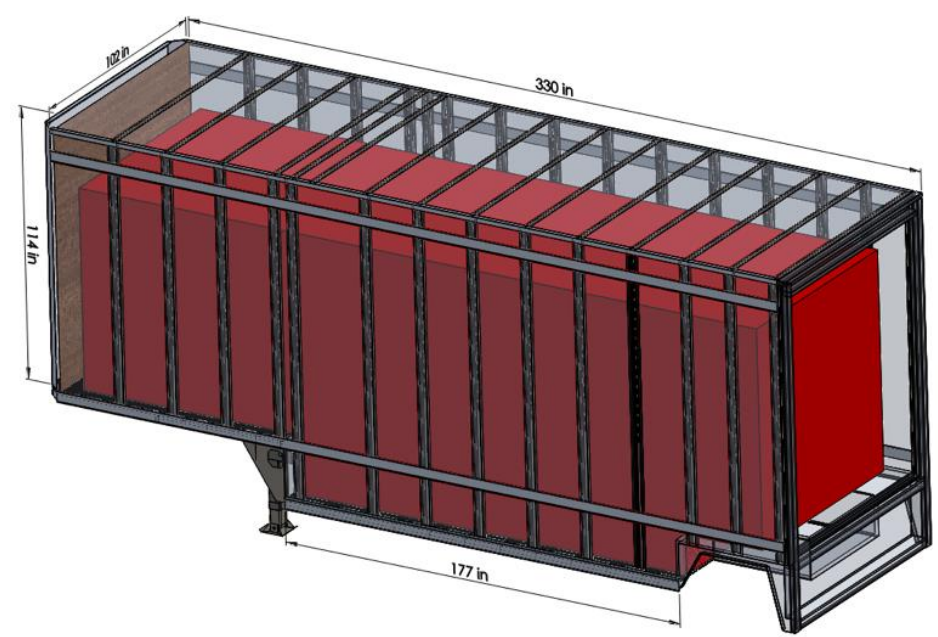

Figure 6. 3-D model of the 28-ft drop-frame trailer in SolidWorks

\subsubsection{Experimental Validation of the 28-ft Doubles Model}

Results collected in our truck field test are used to validate the 28-ft doubles model developed in TruckSim. As shown in Figure 7 (top image), a pair of outriggers were attached underneath the trailers in the field test to prevent the vehicles from actually rolling over by providing counterbalance moment when one side contacts the ground. For comparison of outrigger contact forces, TruckSim built-in outrigger components, acting as two points fixed to the trailer body at certain distances, are added to the model, as shown in Figure 7 (bottom image).

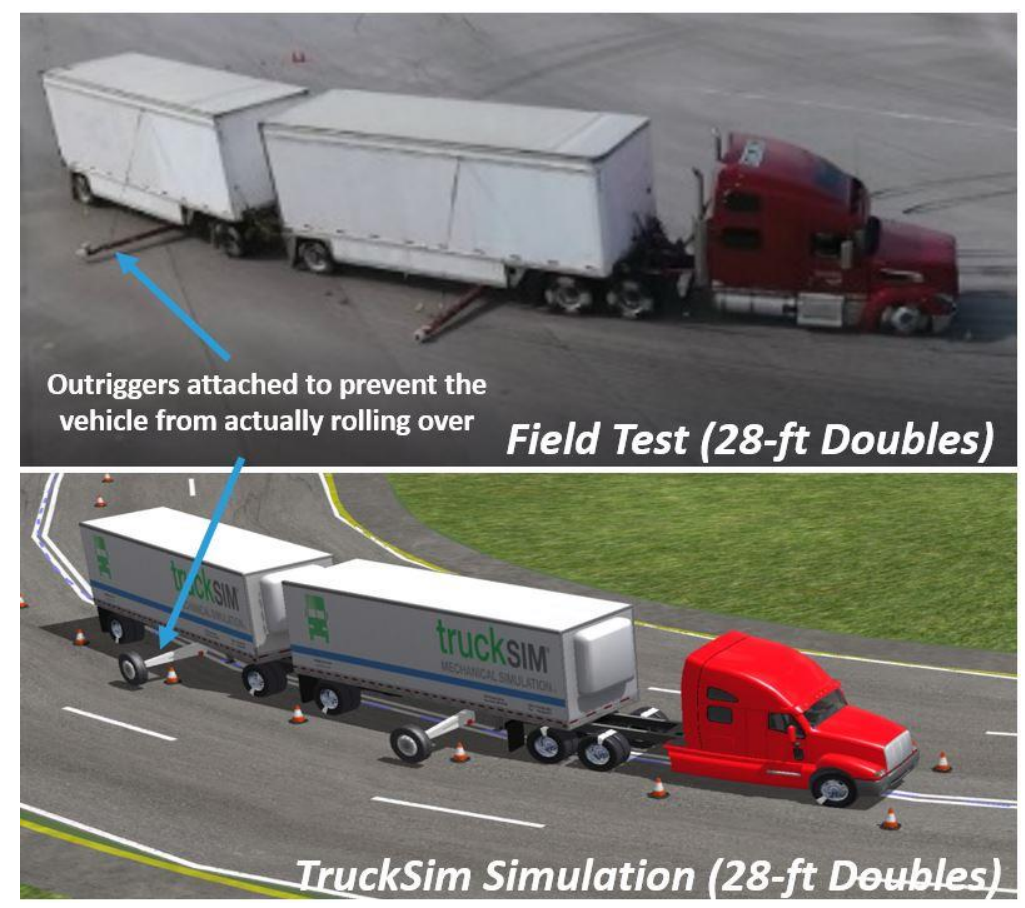

Figure 7. Outrigger-integrated 28 - $\mathrm{ft}$ doubles in testing field and TruckSim 
In addition, a load frame was designed and placed inside the testing trailer to ensure that the outrigger-attached vehicle would possess the same sprung mass properties (such as sprung weight, CG position, and moments of inertia) as that of the normal highway loading condition, shown in Figure 8. A steering robot was also employed in the test to allow for accurate and repeatable steering input without involving the driver's response. The steering wheel angle data is applied to the model as the input.

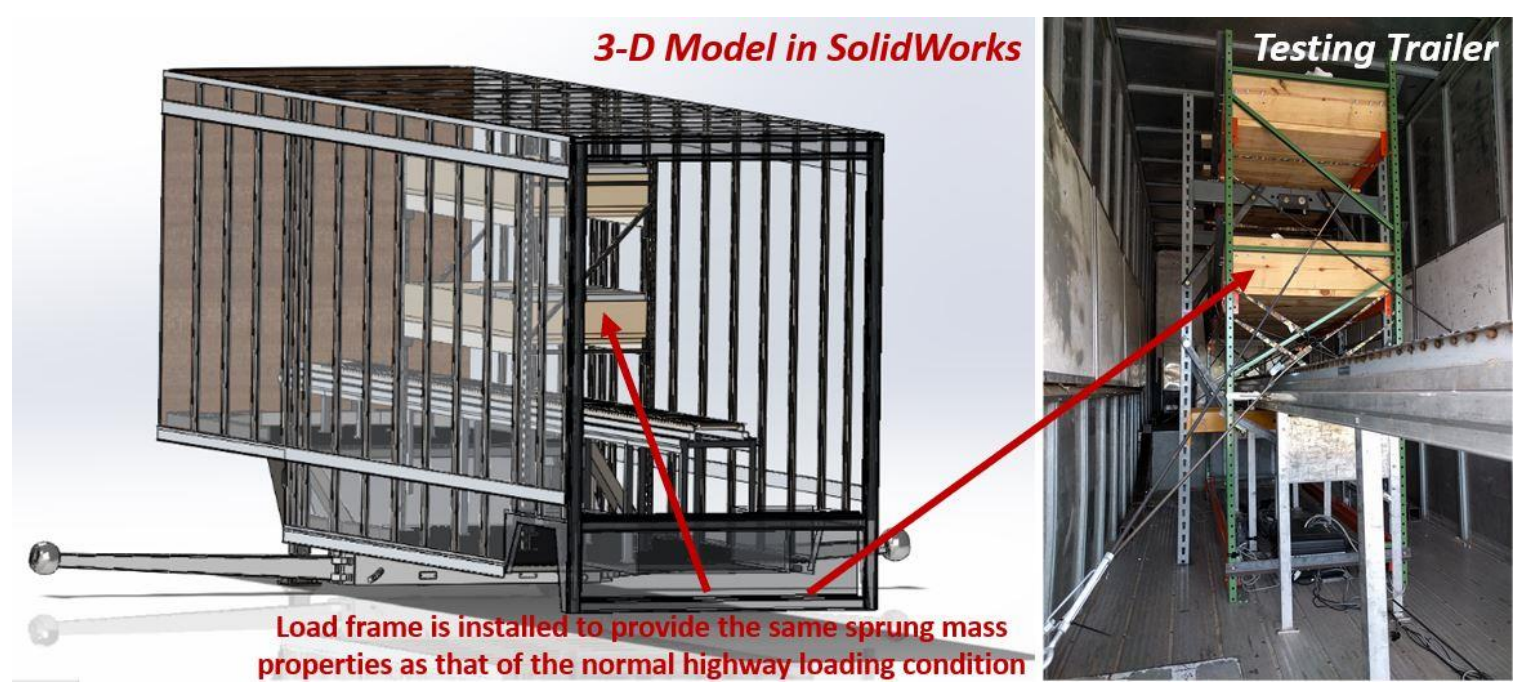

Figure 8. Load frame installed in the testing trailer to provide the same sprung mass properties as that of the normal highway loading condition

The model is validated by comparing the simulation results with experiments. As shown in Figure 9, good agreement is obtained between the two in lateral accelerations, articulation angles, and outrigger contact force. Results in Figure 9 indicate that only the front trailer outrigger contacts the ground in the test maneuver. It is true regarding the A-train that the front trailer is supposed to have better roll stability than the rear trailer due to its coupling with the tractor by the fifth wheel. However, the drop in driving speed and time delay to action make the rear trailer subject to a smaller lateral acceleration than the front trailer, thereby preventing rear trailer outrigger contact during this test maneuver. In addition, the front trailer in response to the outrigger contact $(\mathrm{t}=3.7 \mathrm{~s})$ exhibits a fluctuation of the lateral acceleration, which is not consistent with the model's prediction. This inconsistency is mainly due to the fact that the outrigger model in TruckSim is not capable of simulating the forces resulting from bending and interactions among internal components of the outrigger. 


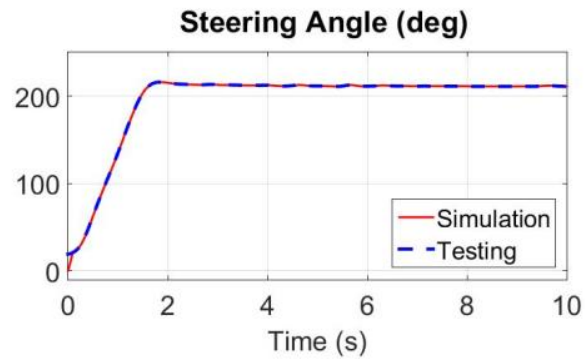

Articulation Angle of Tactor and Front Trailer (deg)

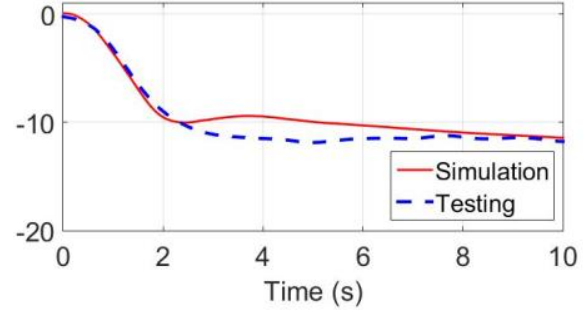

Articulation Angle of Front and Rear Trailers (deg)

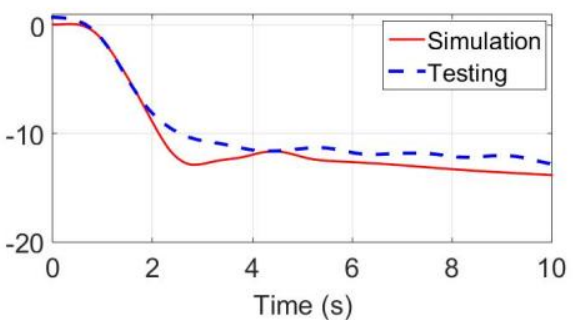

Front Trailer Outrigger Contact Force (Ibf)

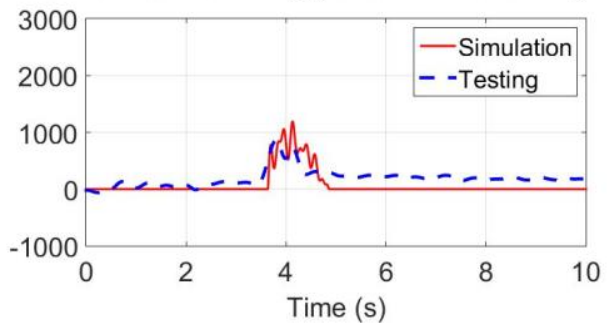

Driving Speed (mph)

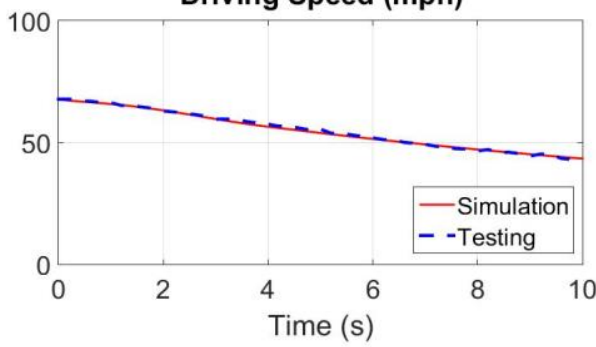

Tractor Lateral Acceleration (g)

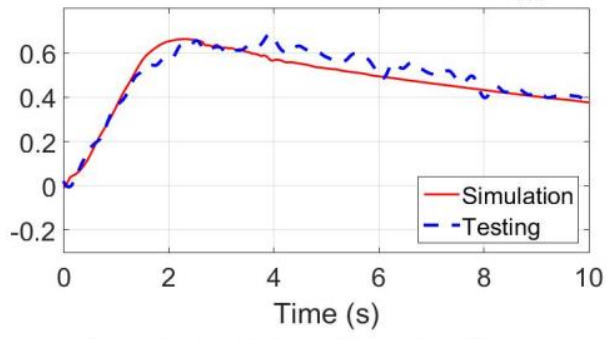

Front Trailer Lateral Acceleration (g)

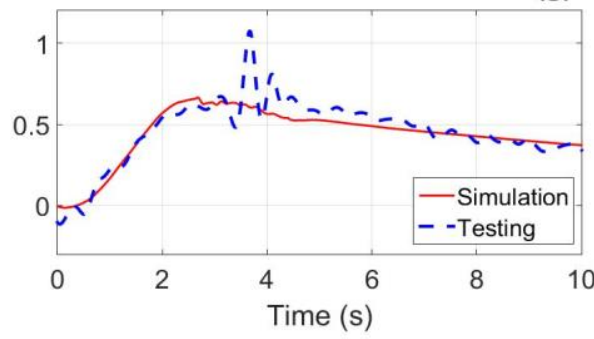

Rear Trailer Lateral Acceleration (g)

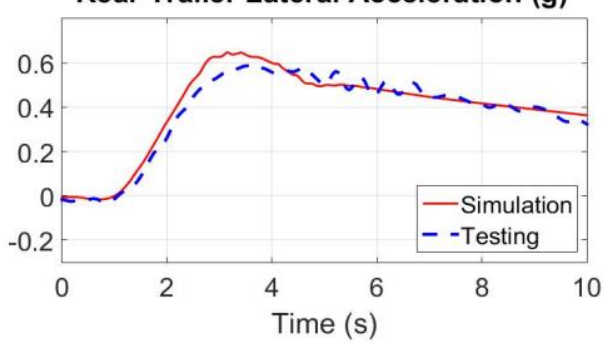

Figure 9. Comparison results between simulation and experiment for a step steering maneuver

\subsection{8-ft Triple-trailer Truck Model}

Adding another A-dolly and 28-ft trailer to the previously-developed 28-ft doubles model produces the 28-ft triple model, as shown in Figure 10. The added trailer and dolly have the same dynamic properties as those used in 28 -ft doubles.

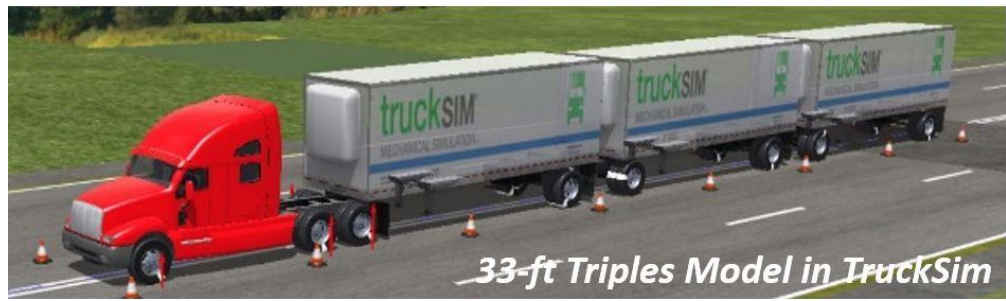

Figure 10. The 28-ft triple-trailer truck model in TruckSim 


\subsection{3-ft Double-trailer Truck Model}

In the last simulation, TruckSim is used to establish the model of 33-ft double-trailer truck, which is shown in Figure 11. As compared to the $28-\mathrm{ft}$ trailer, the $33-\mathrm{ft}$ trailer has a longer wheelbase and different sprung mass properties in accordance with its extra length.

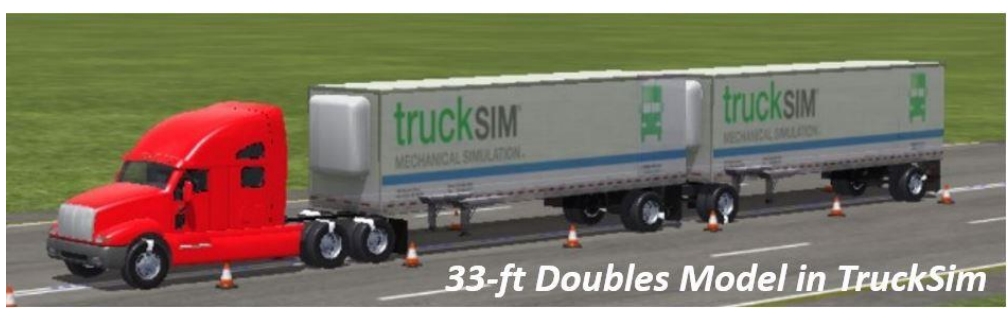

Figure 11. The 33-ft double-trailer truck model in TruckSim

In order to perform the dynamic performance comparison with the 28 - $\mathrm{ft}$ trailer, two load conditions are applied for the $33-\mathrm{ft}$ trailer in the study:

- Carrying less dense cargo but with the same weight (6000 lb.) as the $28-\mathrm{ft}$ trailer (referred to as " $33-\mathrm{ftD} 1$ ")

- Carrying heavier weight (6949 lb.) but with the same load density as the 28 -ft trailer (referred to as "33-ftD2")

A 3-D model of the 33-ft drop-frame trailer is created in SolidWorks, as shown in Figure 12, to determine the dimensional inertial (CG) properties in the same manner as the $28 \mathrm{ft}$ trailer. Parameters of the trailer with the load conditions as mentioned earlier are provided in Table 3.

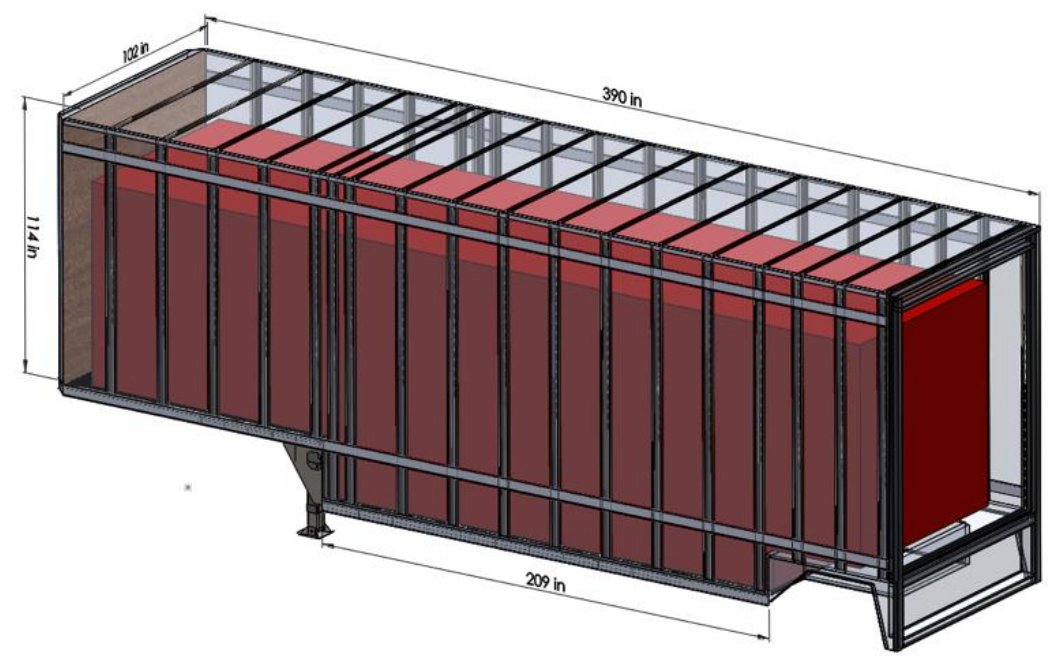

Figure 12. 3-D model of the 33-ft drop-frame trailer in SolidWorks 
Table 3. Parameters for the 33-ft drop-frame trailer simulation

\begin{tabular}{|c|c|c|}
\hline Trailer Body Properties & $\begin{array}{c}\text { 33-ftD1 (same load as } \\
\text { 28-ft) }\end{array}$ & $\begin{array}{c}\text { 33-ftD2 (same load } \\
\text { density as 28-ft) }\end{array}$ \\
\hline Sprung Weight & $15775 \mathrm{lb}$. & $16855 \mathrm{lb}$. \\
\hline CG Height to the Ground & $6.22 \mathrm{ft}$ & $6.27 \mathrm{ft}$ \\
\hline CG Long. Distance to Kingpin & $14.37 \mathrm{ft}$ & $14.37 \mathrm{ft}$ \\
\hline Distance from Kingpin to Axle & $28 \mathrm{ft}$ & $28 \mathrm{ft}$ \\
\hline Roll Moment of Inertia & $279126 \mathrm{lb} \cdot \mathrm{ft}^{2}$ & $291646 \mathrm{lb} \cdot \mathrm{ft}^{2}$ \\
\hline Yaw Moment of Inertia & $1486997 \mathrm{lb} \cdot \mathrm{ft}^{2}$ & $1566562 \mathrm{lb} \cdot \mathrm{ft}^{2}$ \\
\hline Pitch Moment of Inertia & $1547891 \mathrm{lb} \cdot \mathrm{ft}^{2}$ & $1629894 \mathrm{lb} \cdot \mathrm{ft}^{2}$ \\
\hline Load Weight & $6000 \mathrm{lb}$. & $6949 \mathrm{lb}$. \\
\hline Load Density & $3.29 \mathrm{lb} . / \mathrm{ft}^{3}$ & $3.81 \mathrm{lb} . / \mathrm{ft}^{3}$ \\
\hline
\end{tabular}

\section{Simulation Results and Analysis}

Double lane change (DLC) and J-turn maneuvers are adopted in the study to assess the lateral performance of the LCVs [20]. The paths of the two maneuvers are shown in Figure 13a and 13b, respectively. The safety-related performance is compared among those aforementioned truck configurations for the selected maneuvers at various speeds, in terms of rearward amplification, rollover likelihood, and off-tracking.

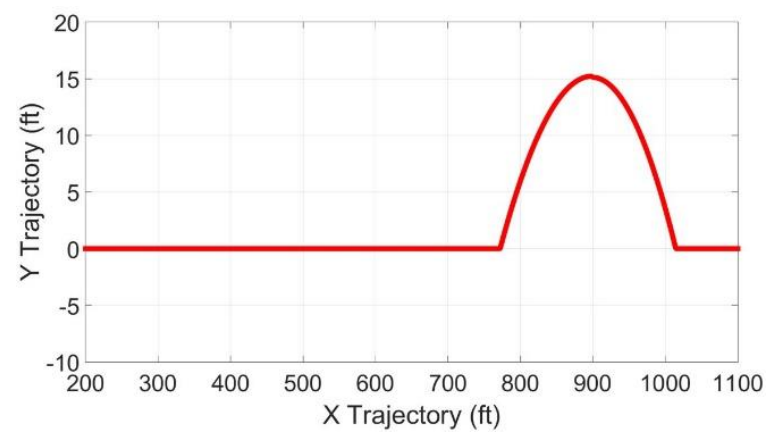

(a)

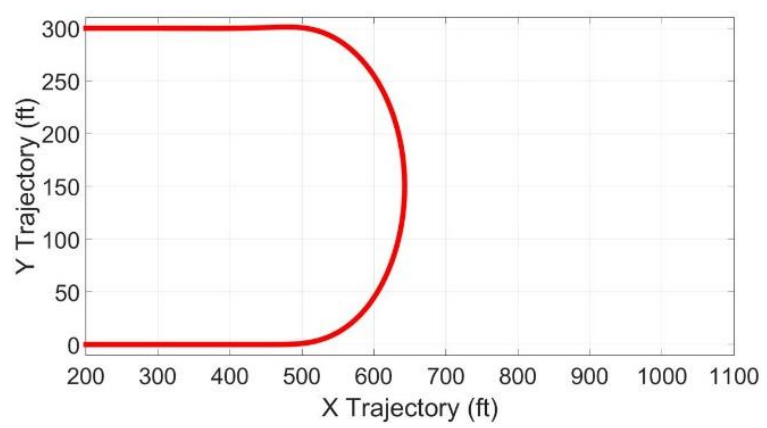

(b)

Figure 13. Paths of (a) double lane change and (b) J-turn maneuvers

\subsection{Simulation Study on Rearward Amplification}

Rearward amplification is a tendency of the rearmost trailer to laterally over-respond in obstacleavoidance maneuvers, which is an undesirable dynamic behavior for LCVs [21]. A severe rearward amplification imposes more risk for the rearmost trailer to hit other objects on the road or to roll over. The rearward amplification needs to be small such that the rearmost trailer can follow the 
tractor's path with adequate fidelity. Figure 14 a-d show the time trace of the lateral accelerations of the tractor and the last trailer responding to the double lane change maneuver at $50 \mathrm{mph}$. For all LCVs, a time lag is observed between the actions of the tractor and the last trailer, mainly due to the tractrix geometry that basically governs the kinematic motion of the LCVs. It is significant to note that all truck combinations exhibit an exaggerated lateral acceleration response on the rearmost trailer, which is known as the rearward amplification phenomenon. Among the truck configurations, the 28 -ft triples have the highest peak-lateral-acceleration difference between the tractor and the rearmost trailer during the lane change maneuver.
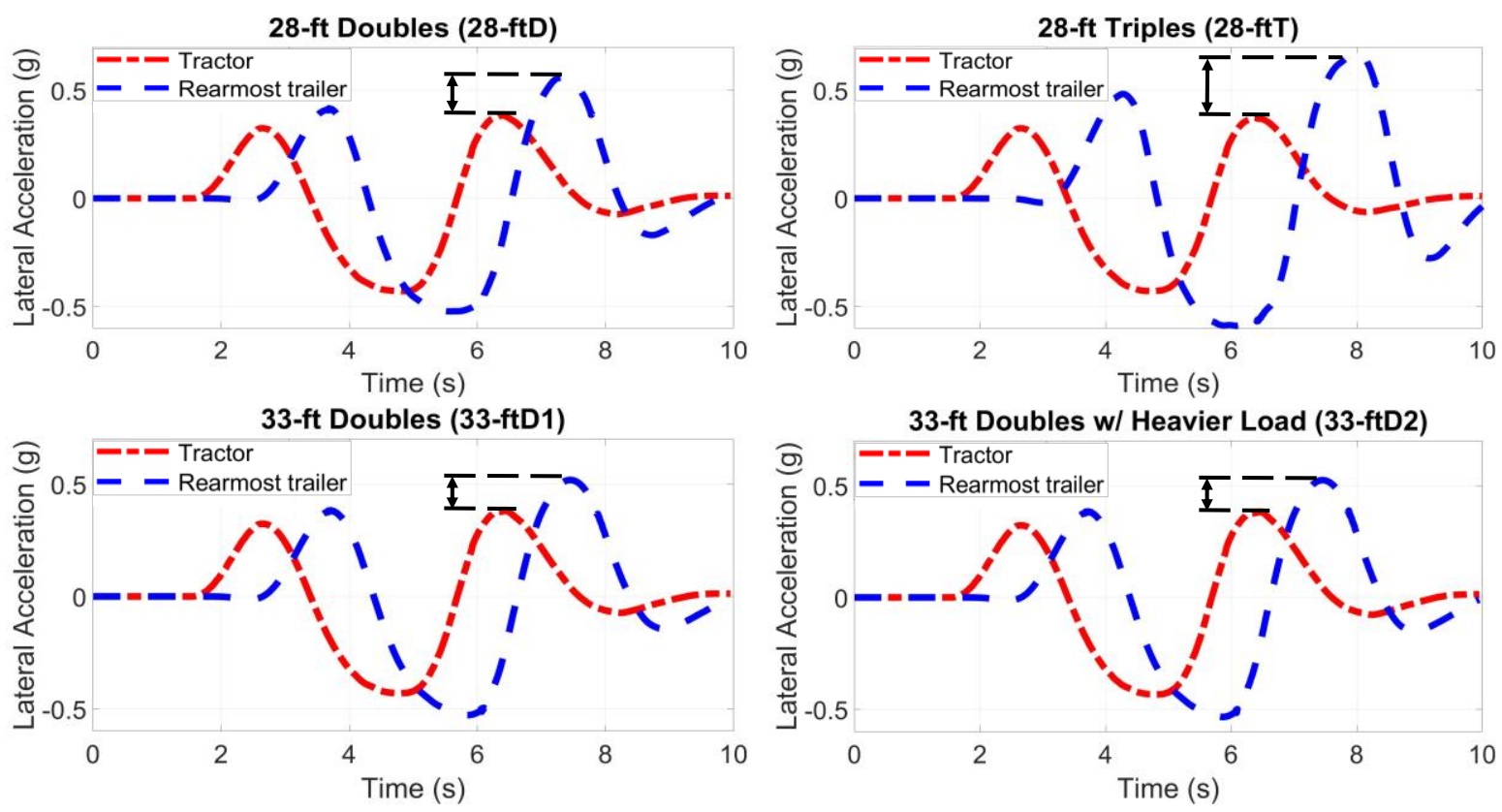

Figure 14. Time trace of the lateral acceleration of the tractor and rearmost trailer for double lane change at $50 \mathrm{mph}$

To quantify the severity of the rearward amplification, the amplification factor (AF), a ratio of peak lateral acceleration of the rearmost trailer divided by that of the tractor, is introduced [21]:

$$
\text { Amplification Factor }(A F)=\frac{\text { Peak }\left(\text { Ay } y_{\text {the last trailer })}\right.}{\text { Peak }\left(\text { Ay } y_{\text {tractor }}\right)}
$$

Lower values of AFs imply better performance for the rearmost trailer to follow the tractor's path. The best value is one where no rearward amplification occurs. Figure 15 summarizes the AFs of the truck configurations for the double lane change at speeds ranging from 35 to $55 \mathrm{mph}$. In the following figures, the 28 -ft doubles, 33 -ft doubles, and 28 -ft triples are abbreviated by " $28-\mathrm{ftD}$," "28-ftT," and "33-ftD." As shown in Figure 15, at the speed of 35mph, the value of AF is below 
1, and no rearward amplification occurs. As the speed increases, the value of AF increases over 1, resulting in the trailer being subjected to a larger lateral acceleration and thus more prone to rollover than the tractor. Compared to the other configurations, the 28 -ft triples have the lowest speed threshold of rearward amplification while exhibiting the largest AF at subsequent speeds, making the rear trailer most likely to collide with obstacles on the road or rollover. At the speed of $55 \mathrm{mph}$, the triples exhibit a rearward amplification of $2.6,51 \%$ more than that of the 28 - $\mathrm{ft}$ double. The 33-ft doubles with longer wheelbase display favorable performance in the rearward amplification, with the AF approximately $9 \%$ less than that of the 28 - $\mathrm{ft}$ doubles. No explicit difference of AF is observed between the 33-ft doubles with different load conditions. In summary, the triples with two more yaw articulation points have a greater rearward amplification than the doubles, and increasing the trailer length from 28 - $\mathrm{ft}$ to $33-\mathrm{ft}$ slightly mitigates the rearward amplification for the double-trailer combination.

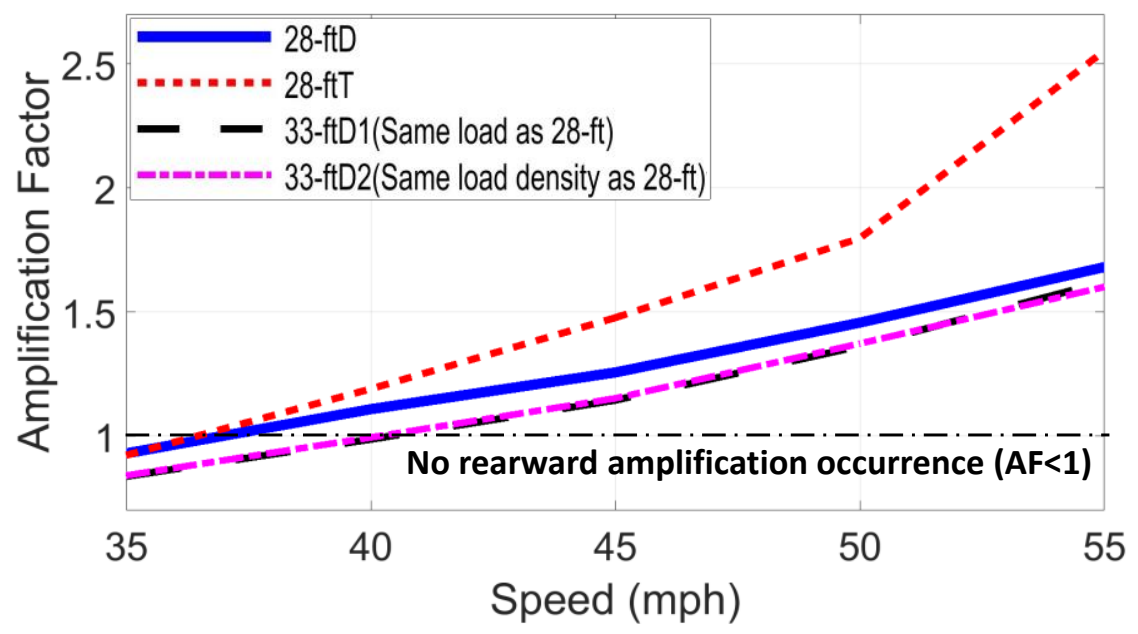

Figure 15. Simulation results of AF for DLC maneuver at speeds from 35 to $55 \mathrm{mph}$

The AFs extracted from peak lateral accelerations during the J-turn maneuver at various speeds are summarized in Figure 16. As shown, the AF stays close to 1 and has minimal change with increasing speed for all truck configurations. It is concluded that the rearward amplification of the LCVs is not easily elicited in a slow and steady steering maneuver such as the J-turn maneuver considered in this study. 


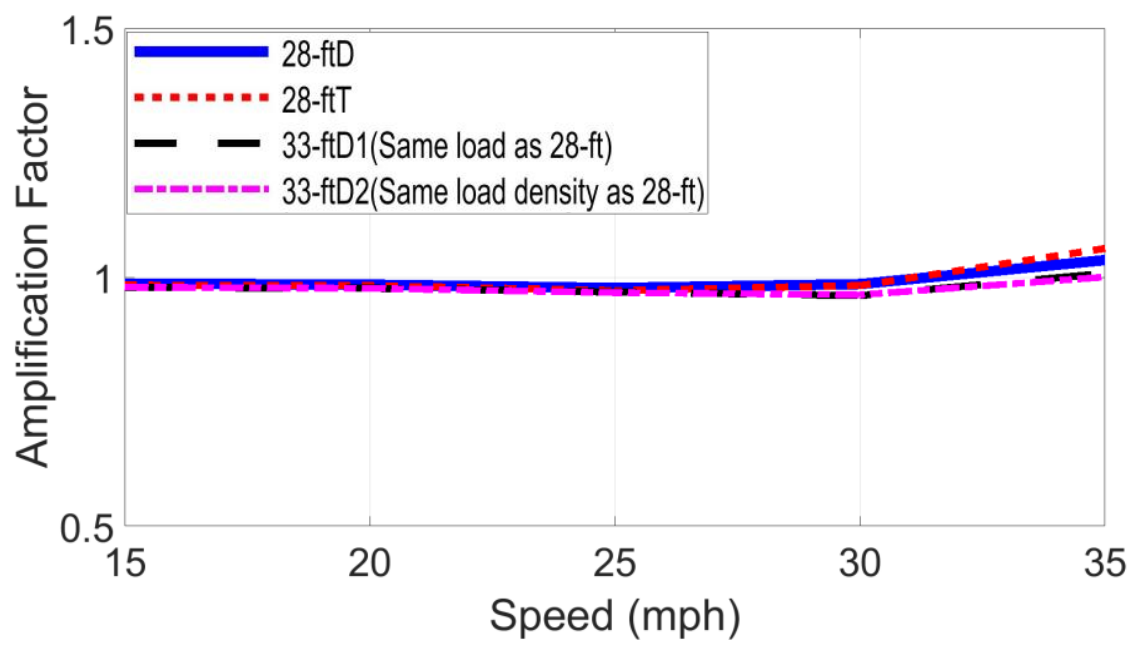

Figure 16. Simulation results of AF for J-turn maneuver at speeds from 15 to $35 \mathrm{mph}$

\subsection{Simulation Study on Rollover Likelihood}

The rollover happens as tires lose contact with the ground, causing the truck to flip over sideways completely [22]. The severity and susceptibility to rollover depend on the load's CG height, steering sensitivity, axle track width, and driving speed. For quantitatively evaluating the potential likelihood of a rollover event, a metric known as the rollover index is used [23]. The rollover index derived from the side-to-side vertical tire forces is defined as:

$$
\text { Rollover Index }(R I)=\frac{\left|F_{z, R}-F_{z, L}\right|}{F_{z, R}+F_{z, L}}
$$

where $F_{z, R}$ and $F_{z, L}$ denote the vertical tire forces on the passenger and driver sides, respectively. During straight driving and assuming an in-center load, the vertical tire forces are equal from side to side, and the RI is zero. If tires on either side lift off the ground or rest on the road surface with negligible load, the RI equals 1 . Figure 17 shows the time-history results of vertical tire forces on the rearmost trailer axle when performing the J-turn maneuver at $35 \mathrm{mph}$. In response to the J-turn maneuver, the rearmost trailer has the vertical tire force on the inner side decreased, while generating more vertical forces upon the outer-side tires. At $\mathrm{t}=7.6 \mathrm{~s}$, the wheel lift occurs on the driver side for 28 -ft triples; at this moment, the RI reaches 1, which is not observed for the other truck configurations. 

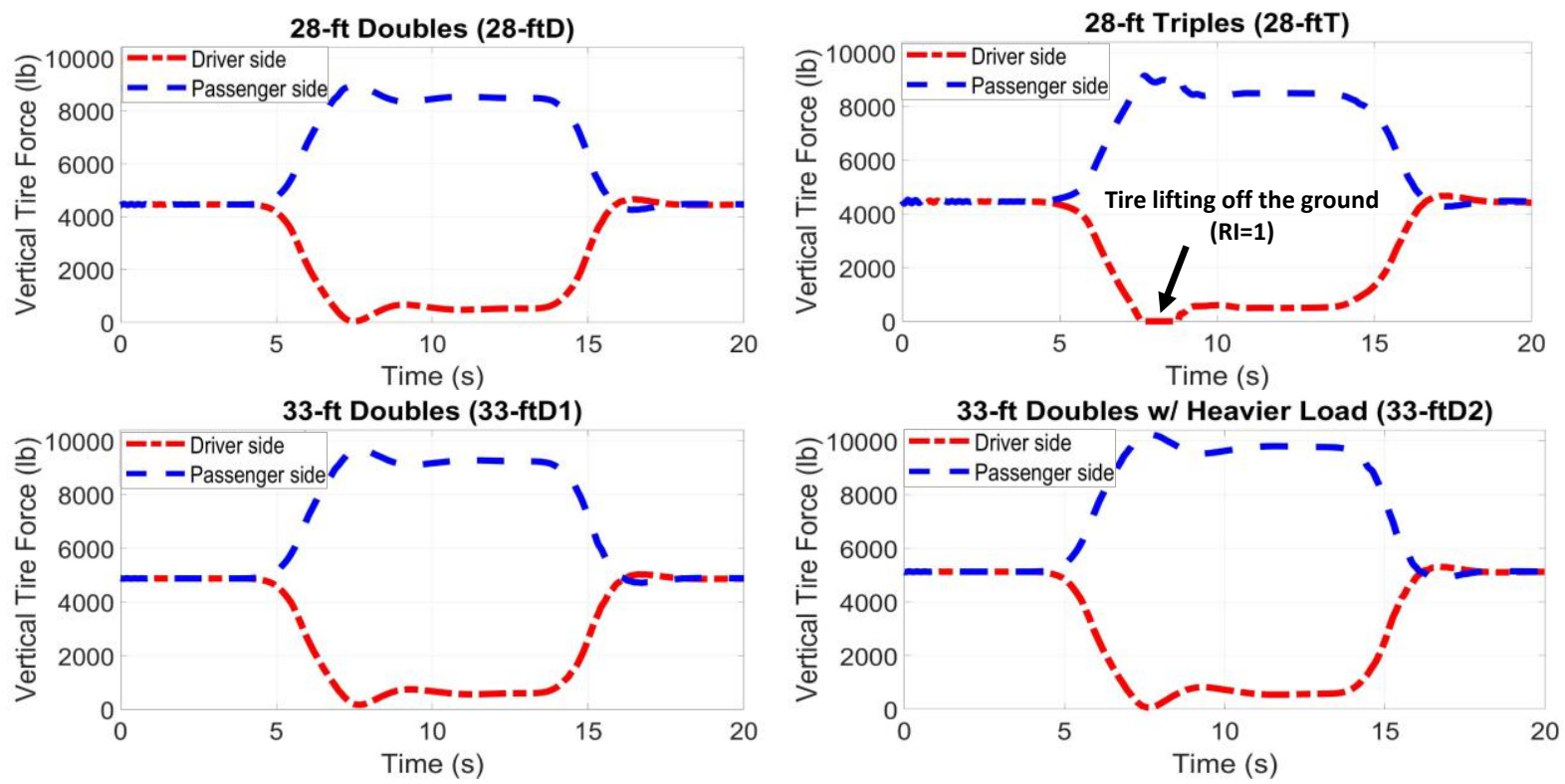

Figure 17. Time trace of the vertical tire force on the rearmost trailer for J-turn at $35 \mathrm{mph}$

Figures 18 provides a summary of the maximum RIs of the truck configurations for double lane change maneuver at speeds between 35 and $55 \mathrm{mph}$. Only simulation results on the rearmost trailer are presented here due to the rollover always occurring at the rearmost trailer in the simulation. The maximum RI of 0.8 is considered as an upper limit that brings the truck into an unsafe condition where it has a high likelihood of rollover. As shown in Figure 18, the maximum RI increases with increasing speed, while the triple configuration, with a nearly 3 -mph lower rollover speed threshold, is more likely to roll over than the double configuration. Additionally, the longer wheelbase makes the $33-\mathrm{ft}$ doubles tolerate a 1 -mph higher rollover speed better than the $28 \mathrm{-ft}$ doubles. Comparing the 33 -ft doubles with different load conditions, the $33-\mathrm{ft}$ doubles with the heavier load (33-ftD2) exhibit a slightly higher maximum RI than the 33-ft with the same load as the $28-\mathrm{ft}$ (33-ftD1). The results in Figure 18 are consistent with those in Figure 15 since the rearward amplification is believed to be the primary cause of rollover of LCVs in the lane change maneuver. 


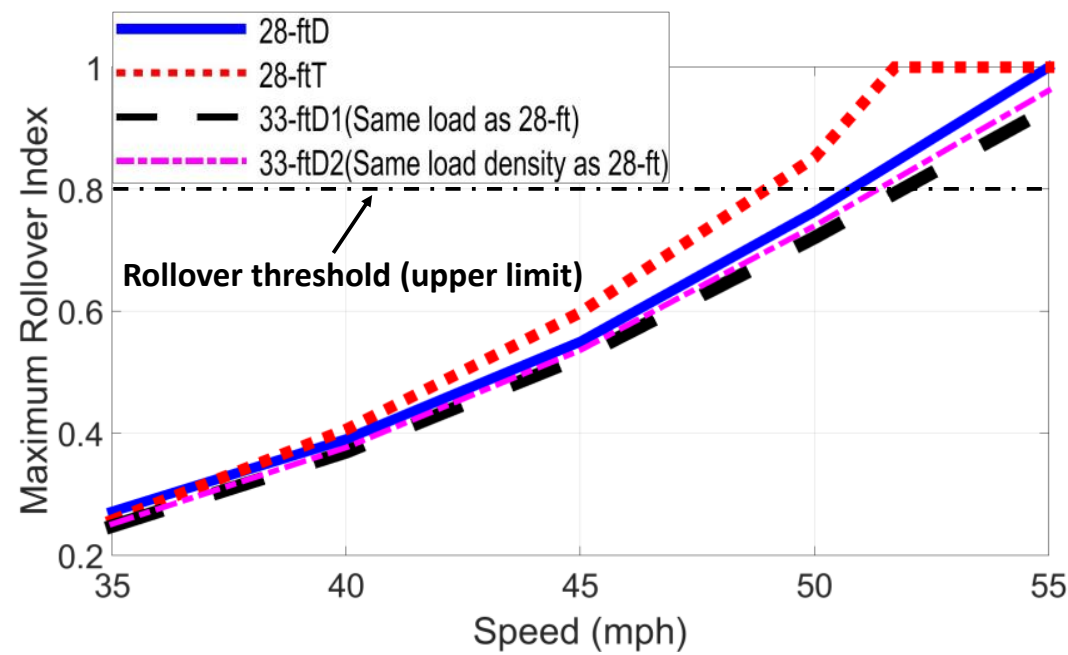

Figure 18. Simulation results of maximum RI for DLC maneuver at speeds from 35 to $55 \mathrm{mph}$

Figure 19 summarizes the results of maximum RIs for the J-turn maneuver. The difference among the configurations is not evident at speeds below $25 \mathrm{mph}$, while results over $25 \mathrm{mph}$ are consistent with those of the double lane change maneuver.

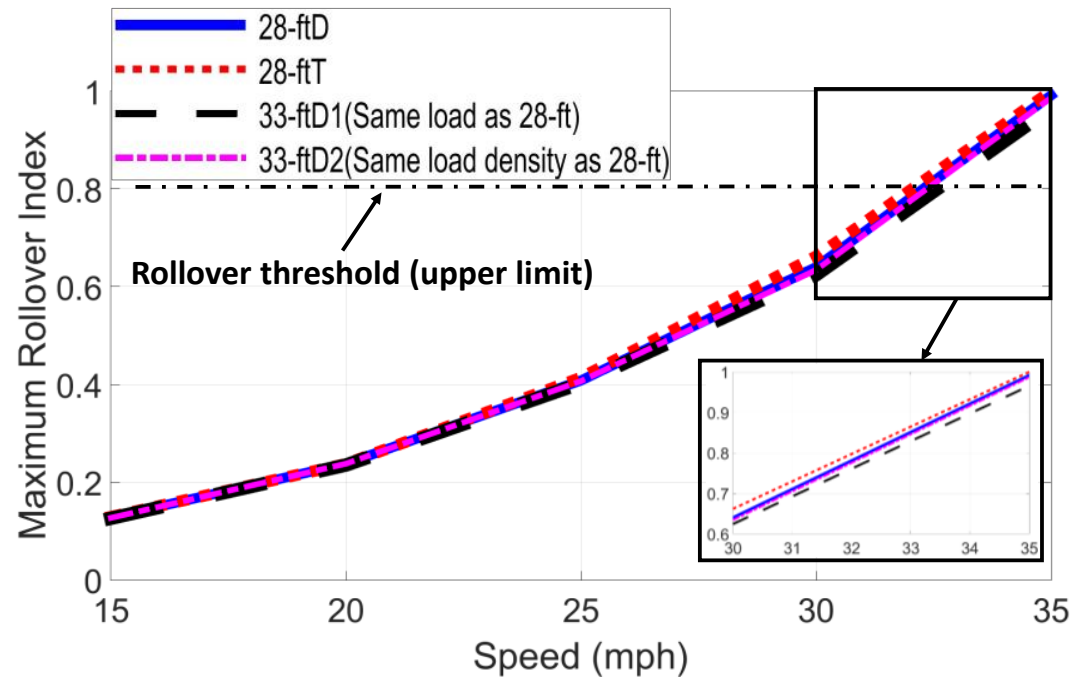

Figure 19. Simulation results of maximum RI for J-turn at speeds from 15 to $35 \mathrm{mph}$

\subsection{Simulation Study on Off-tracking}

This section examines the tracking fidelity of the truck combinations considered in this paper. The double lane change and J-turn maneuvers in Figure 13 are applied to evaluate their off-tracking performance as determined by the path difference between the centers of the steering axle and the rear trailer axle. The off-tracking falls into two categories: inboard and outboard off-tracking. As the name implies, the inboard off-tracking indicates that the rear trailer axle follows inside the path 
of the tractor steering axle, typically occurring at low-speed turns. A large inboard off-tracking is unwanted when the driver negotiates a low-speed turn in an intersection or interchange because the truck may require more road space than what is available, resulting in a collision with other vehicles or obstacles on the road. If the truck performs a high-speed or a sudden swerve, there is a tendency for the rear trailer axle to sway outward of the path of the tractor steering axle, which is referred to as the outboard off-tracking. A large outboard off-tracking will cause the trailer to hit the object that the driver attempts to avoid in an avoidance maneuver [24]. Figure 20 shows the outboard off-tracking when the trucks negotiate with the double lane change at $50 \mathrm{mph}$. At $\mathrm{X}=420 \mathrm{ft}$, the rear trailer axle of all truck combinations tracks outboard of the tractor steering axle. The amount of the trailer overshoot is 4.1 feet for the 28 -ft triples, apparently larger than the other truck configurations.
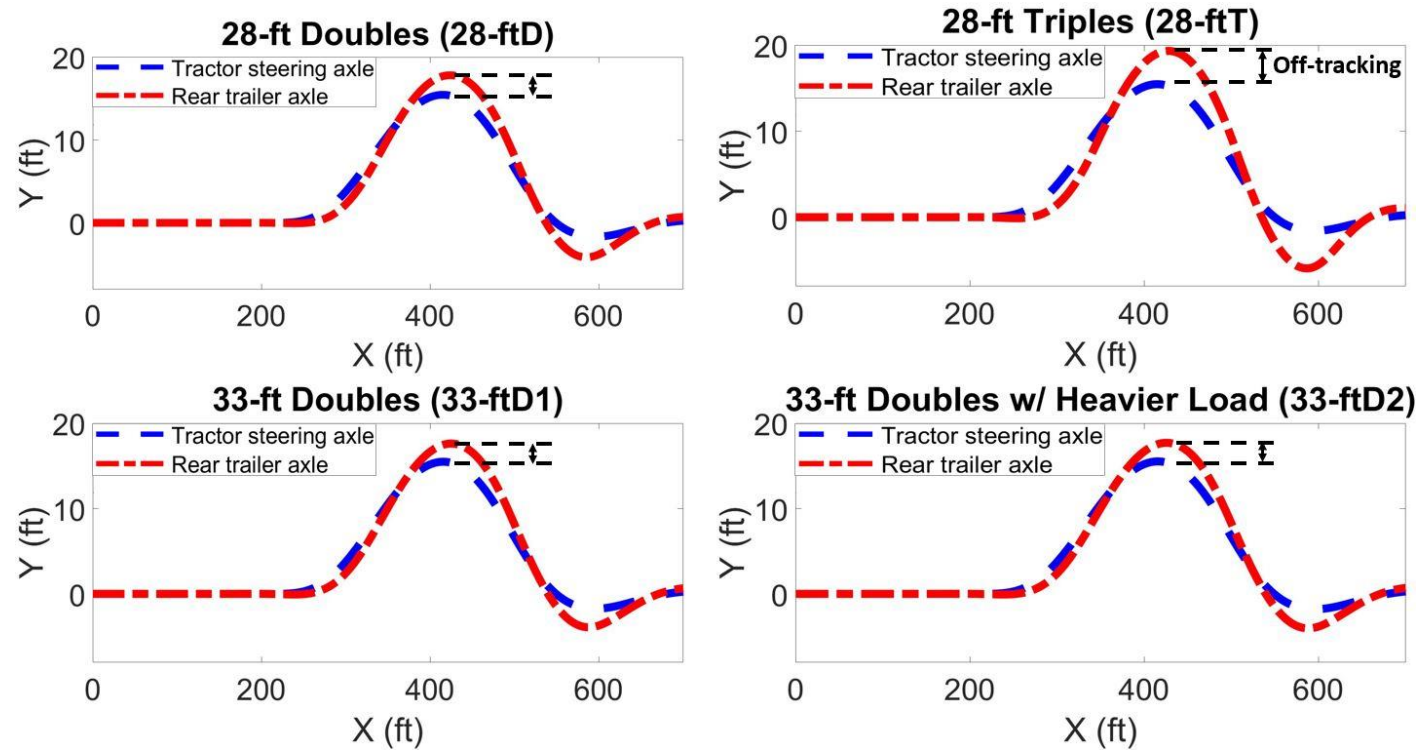

Figure 20. Paths of the tractor steering axle and rear trailer axle for double lane change at $50 \mathrm{mph}$

Figure 21 compares the maximum outboard off-tracking among the truck configurations for the double lane change maneuver. Trends of the results in Figure 21 are similar with those of rearward amplification due to the fact that the lateral movement of the rear trailer is strongly tied to the rearward amplification at the high-speed lane change maneuver. A larger rearward amplification promotes the body yaw motion of the rearmost trailer (more lateral CG displacement) with tires sliding outside of the tractor path at a certain road roughness level. Thus, the 28 -ft triples have the worst off-tracking performance among the others, as shown in Figure 21. Interestingly, the 28-ft doubles exhibit a $1.5 \%$ larger maximum off-tracking than the $33-\mathrm{ft}$ doubles, indicating that the 
extra length of the trailer results in a better outboard off-tracking performance. No discernible difference is found between the $33-\mathrm{ft}$ doubles with the different load conditions.

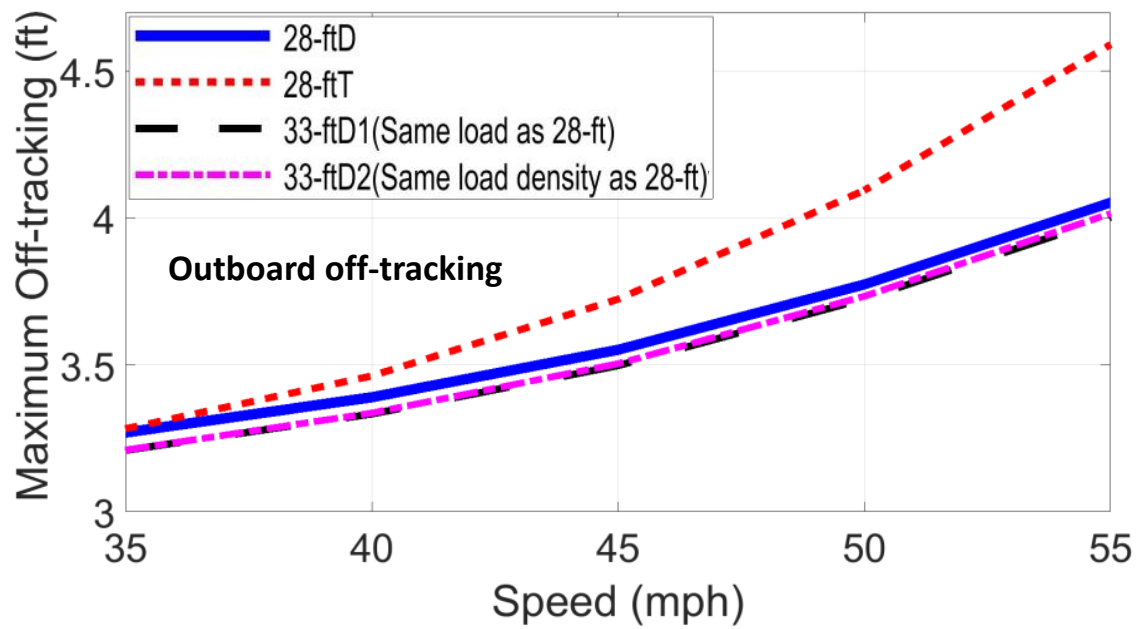

Figure 21. Simulation results of maximum off-tracking for DLC maneuver at speeds from 35 to $55 \mathrm{mph}$ Figure 22 shows the simulation results of maximum off-tracking for the J-turn maneuver at speeds from 15 to $35 \mathrm{mph}$. The positive value represents the outboard off-tracking, while the negative value indicates the inboard off-tracking. At speeds below $32 \mathrm{mph}$, the tractor-semi-trailer combinations have the inboard off-tracking, while the outboard off-tracking occurs for the 28-ft double and triples when the speed goes over $32 \mathrm{mph}$. As shown in Figure 22, the 28-ft triples have nearly the same amount of inboard off-tracking as the 33-ft doubles, which is far larger than the 28-ft doubles. However, the triple combination exhibits a quicker transition from the inboard to the outboard off-tracking with increasing speed than the double configurations.

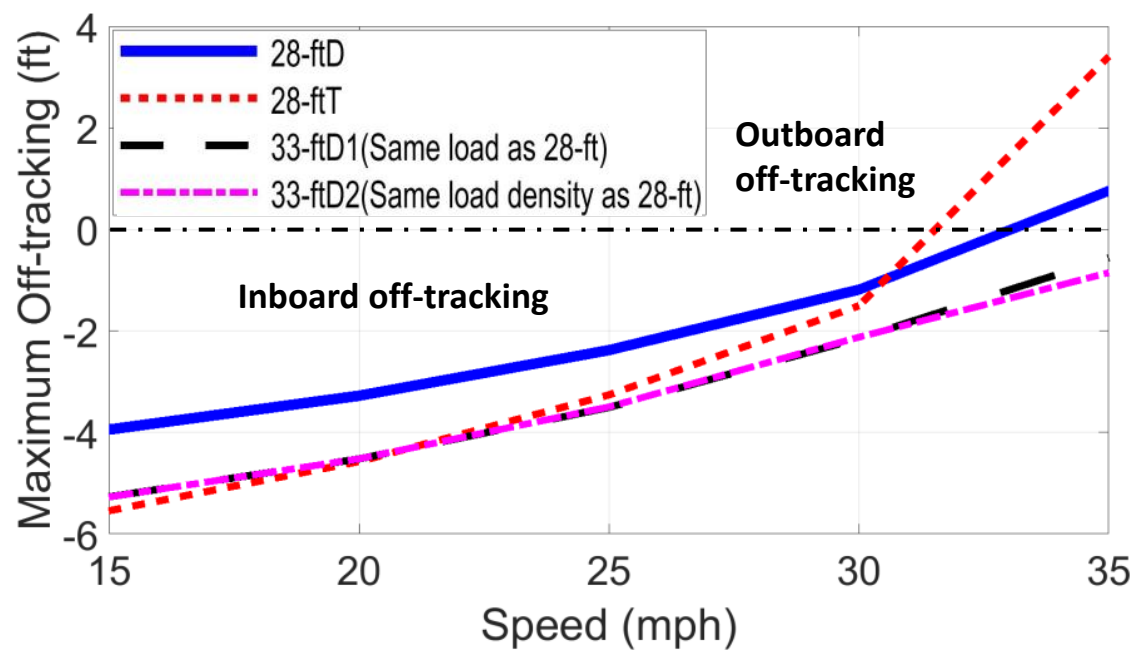

Figure 22. Simulation results of maximum off-tracking for J-turn at speeds from 15 to $35 \mathrm{mph}$ 


\section{Conclusions}

This paper presents the results of a comparison study on the lateral characteristics of 28 -ft doubles, $28-\mathrm{ft}$ triples, and $33-\mathrm{ft}$ doubles. The results are critical for better understanding rollover characteristics and off-tracking performance of Long Combination Vehicles (LCVs). For this study, a validated multi-domain dynamic model is developed in TruckSim. The model is used to emulate and evaluate the lateral performance of the selected LCVs in three specific aspects: rearward amplification, rollover likelihood, and off-tracking. The key findings of this study are provided in Table 4, while the simulation results are summarized as follows:

(1) Compared with the double combination, the 28 -ft triples exhibit a larger $\mathrm{AF}$ and worse transient side-to-side dynamics because they have two more yaw articulation points.

(2) Increasing the trailer length from 28 to 33 feet does not increase the rearward amplification, rollover propensity, or outboard off-tracking, mainly because of the increased wheelbase. The extra length of the trailer, however, increases inboard off-tracking.

(3) For heavier load conditions, 33-ft doubles do not exhibit more off-tracking or rearward amplification, but the rollover likelihood could increase if the added load results in a higher CG.

Table 4. Comparison results of lateral characteristics of the LCVs

\begin{tabular}{|c|c|c|c|c|}
\hline LCVs Characteristics & 28-ftD & 33-ftD1 & 33-ftD2 & 28-ftT \\
\hline Rollover likelihood & Fair & Best & Good & Worst \\
\hline Rearward amplification & Good & Best & Best & Worst \\
\hline Off-tracking (DLC) & Good & Best & Best & Worst \\
\hline Off-tracking (J-turn) & Best & Good & Good & Worst \\
\hline
\end{tabular}

\section{References}

1. Chambers, M., Goworowska, J., Rick, C., and Sedor, J., "Freight Facts and Figures, 2015," 2016.

2. Sprung, J., "Freight Facts and Figures, 2017," 2018.

3. Harwood, W., "Review of Truck Characteristics as Factors in Roadway Design," Transportation Research Board, vol. 505, 2003.

4. Pape, D., Arant, M., Brock, W., Broshears, E., Chitwood, C., Colbert, J., and Hathaway, R., "U32: Vehicle Stability and Dynamics-Longer Combination Vehicles," Oak Ridge National Laboratory (ORNL); National Transportation Research Center, 2011. 
5. Knipling, R., "Twin 33 Foot Truck Trailers: Making U.S. Freight Transport Safer and More Efficient," Americans for Modern Transportation, 2016.

6. "Feasibility of Allowing the Use of Twin 33-foot Trailers in California,"http://www.dot.ca.gov/newtech/researchreports/preliminary_investigations/docs/f easibility_of_allowing the use_of_twin_33-foot_trailers_in_california_pi.pdf, accessed Aug. 2018.

7. Kati, S., "Definitions of Performance-based Characteristics for Long Heavy Vehicle Combinations," Chalmers University of Technology, Tech. Rep, 2013.

8. Babesse, S., and Ameddah, D., "Improvement of LQR Active Anti-roll Control of a Singleunit Heavy Vehicle by Means of a Trained Artificial Neuronal Network,” International Journal of Vehicle Safety 9, no. 2, pp. 166-179, 2016.

9. Federal Motor Carrier Safety Administration, "Large Truck and Bus Crash Facts 2016," https://www.fmcsa.dot.gov/safety/data-and-statistics/large-truck-and-bus-crash-facts-2016, accessed Aug 2018.

10. Fancher, P., and Winkler, C., "Directional Performance Issues in Evaluation and Design of Articulated Heavy Vehicles,” Vehicle System Dynamics 45, no. 7-8, pp. 607-647, 2007.

11. Elkady, M., Elmarakbi, A., and MacIntyre, J., "Enhancement of Vehicle Safety and Improving Vehicle Yaw Behaviour due to Offset Collisions using Vehicle Dynamics," International Journal of Vehicle Safety 6, no. 2, pp. 110-133, 2012.

12. Winkler, B., "Rollover of Heavy Commercial Vehicles," 1999.

13. Harkey, D., Council, F., and Zegeer, C., "Operational Characteristics of Longer Combination Vehicles and Related Geometric Design Issues," Transportation Research Record: Journal of the Transportation Research Board 1523, pp. 22-28, 1996.

14. Daniels, D., "Long Combination Vehicle (LCV) Regulation Training," Delmar Cengage Learning, 1st Edition, 2006.

15. Chen, Y., Hou, Y., Peterson, A., and Ahmadian, M., "Failure Mode and Effects Analysis of Dual Leveling Valve Airspring Suspensions on Truck Dynamics,” Vehicle System Dynamics 57, no. 4, pp. 617-635, 2019.

16. Jazar, N., "Vehicle Dynamics: Theory and Application," Springer, 2017.

17. Descornet, G., "Road-surface Influence on Tire Rolling Resistance," In Surface Characteristics of Roadways: International Research and Technologies, ASTM International, 1990. 
18. Nam, K., Oh, S., Fujimoto, H., and Hori, Y., "Estimation of Sideslip and Roll Angles of Electric Vehicles using Lateral Tire Force Sensors through RLS and Kalman Filter Approaches," IEEE Transactions on Industrial Electronics 60, no. 3, pp. 988-1000, 2013.

19. Chen, Y., Ahmadian, M., and Andrew Peterson, A., "Pneumatically Balanced Heavy Truck Air Suspensions for Improved Roll Stability,” SAE Technical Paper, no. 2015-01-2749, 2015.

20. Elsasser, D., Barickman, F., Albrecht, H., Church, J., Xu, G., and Heitz, M., "Tractor Semitrailer Stability Objective Performance Test Research-Yaw Stability (Part 1),” Accident Reconstruction Journal 24, no. 4, 2014.

21. Wang, Q., and He, Y., “A Study on Single Lane-change Maneuvers for Determining Rearward Amplification of Multi-trailer Articulated Heavy Vehicles with Active Trailer Steering Systems," Vehicle System Dynamics 54, no. 1, pp.102-123, 2016.

22. Chou, C. C., and Yang H. K., "Recent Advancement on Testing and Modelling Methodologies in Rollover Analysis," International Journal of Vehicle Safety 7, no. 3-4, pp. 225-264, 2014.

23. Yu, H., Güvenc, L., and Özgüner, Ü., "Heavy Duty Vehicle Rollover Detection and Active Roll Control,” Vehicle System Dynamics 46, no. 6, pp. 451-470, 2008.

24. De Saxe, C., and Cebon, D., "Estimation of Trailer Off-tracking using Visual Odometry," Vehicle System Dynamics, 2018. 


\section{Appendix A}

Table 5. Parameters for the tractor and dolly simulation

\begin{tabular}{|c|c|c|}
\hline Vehicle Unit & Parameter & Value \\
\hline \multirow{26}{*}{ Semi-Tractor } & Longitudinal distance from the tractor CG to the steering axle & 75.7 in \\
\hline & The vertical distance from the tractor CG to the ground & 39.4 in \\
\hline & Tractor body weight & 14.89 kips \\
\hline & Roll inertia of sprung mass & $1.75 \times 10^{5} \mathrm{lb} \cdot \mathrm{ft}^{2}$ \\
\hline & Pitch inertia of sprung mass & $5.52 \times 10^{5} \mathrm{lb} \cdot \mathrm{ft}^{2}$ \\
\hline & Yaw inertia of sprung mass & $4.99 \times 10^{5} \mathrm{lb} \cdot \mathrm{ft}^{2}$ \\
\hline & Longitudinal distance from the fifth wheel to the steering axle & 199.0 in \\
\hline & The vertical distance from the fifth wheel to the ground & 43.3 in \\
\hline & Fifth-wheel roll freedom & $\pm 0.5 \mathrm{deg}$ \\
\hline & Fifth-wheel pitch freedom & $-11.0 \sim 7.0 \mathrm{deg}$ \\
\hline & Fifth-wheel yaw freedom & $\pm 90.0 \mathrm{deg}$ \\
\hline & Distance from the front drive axle to the steering axle & 186.0 in \\
\hline & Distance from the rear drive axle to the steering axle & 237.8 in \\
\hline & The track width of the steering axle & 83.6 in \\
\hline & Leaf spring stiffness on the steering axle & $1427.5 \mathrm{lb} . / \mathrm{in}$ \\
\hline & Damping coefficient on the steering axle & $97.4 \mathrm{lb} \cdot \cdot \mathrm{s} / \mathrm{in}$ \\
\hline & The lateral spacing between leaf springs on the steering axle & 35.0 in \\
\hline & The lateral spacing between dampers on the steering axle & 43.3 in \\
\hline & The track width of the front drive axle & 72.6 in \\
\hline & Damping coefficient on the front drive axle & $177.0 \mathrm{lb} \cdot \cdot \mathrm{s} / \mathrm{in}$ \\
\hline & The lateral spacing between airsprings on the front drive axle & 30.0 in \\
\hline & The lateral spacing between dampers on the front drive axle & $42.0 \mathrm{in}$ \\
\hline & The track width of the rear drive axle & 72.6 in \\
\hline & Damping coefficient on the rear drive axle & $177.0 \mathrm{lb} \cdot \cdot \mathrm{s} / \mathrm{in}$ \\
\hline & The lateral spacing between airsprings on the rear drive axle & 30.0 in \\
\hline & The lateral spacing between dampers on the rear drive axle & $42.0 \mathrm{in}$ \\
\hline \multirow{6}{*}{ A-Dolly } & Dolly body weight & 1.33 kips \\
\hline & Roll inertia of sprung mass & $2.86 \times 10^{3} \mathrm{lb} \cdot \mathrm{ft}^{2}$ \\
\hline & Pitch inertia of sprung mass & $3.58 \times 10^{3} \mathrm{lb} \cdot \mathrm{ft}^{2}$ \\
\hline & Yaw inertia of sprung mass & $3.58 \times 10^{3} \mathrm{lb} \cdot \mathrm{ft}^{2}$ \\
\hline & The vertical distance from the dolly CG to the ground & 34.8 in \\
\hline & Longitudinal distance from the dolly CG to the hitch & 70.8 in \\
\hline
\end{tabular}

